\title{
First Metatarsalphalangeal Joint Arthrodesis in Rheumatoid Arthritis: A Case Report of Non-Union
}

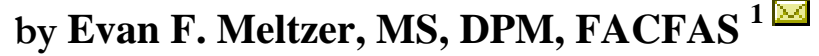

\section{The Foot \& Ankle Journal 1 (4): 3}

The author presents a case report of an attempted arthrodesis of the first metatarsophalangeal joint in a patient with rheumatoid arthritis. Reasons for non union were explored. These include the primary disease process and associated medical and surgical complications. There is conflicting data regarding any direct correlation of patients with rheumatoid arthritis and ethnicity affecting the outcome of surgical arthrodesis.

Key words: Non-Union, rheumatoid arthritis, arthrodesis reproduction in any medium, provided the original work is properly cited. @The Foot \& Ankle Journal (www.faoj.org)

Rheumatoid arthritis (RA) affects people worldwide with a consistent prevalence of $1 \%$. It is most prevalent in highly developed countries such as the United States, England, and Scandinavia. ${ }^{1}$ The prevalence of the disease varies in some populations, and may exceed $5 \%$ in several Native American tribes such as the Yakima, Chippewa and Pima tribes of the United States. ${ }^{1,2}$ In contrast, RA is less common in Japan and Hong Kong and relatively rare in Indonesia and sub-Saharan Africa. ${ }^{1}$ This case report illustrates a surgical non union 8 months following an arthrodesis procedure in a patient with rheumatoid arthritis.

Address correspondence to: Evan F. Meltzer, MS, DPM, FACFAS G.V. (Sonny) Montgomery VA Medical Center, Surgical Service (112) 1500 Woodrow Wilson Drive, Jackson, MS 39216

${ }^{1}$ G.V. (Sonny) Montgomery VA Medical Center, Surgical Service (112), 1500 Woodrow Wilson Drive, Jackson, MS 39216

\section{Case Report}

A 35 year old female with a history of rheumatoid arthritis presented to the podiatry clinic with a chief complaint of pain in the right great toe for the previous 6 months. Her systemic disease was adequately controlled by her primary physician with Etanercept $\left(\right.$ Enbrel $\left.^{\circledR}\right), 25 \mathrm{mg}$ injected subcutaneously twice per week. The patient was also taking Alendronate $\left(\right.$ Foxamax $\left.^{B}\right) 70 \mathrm{mg}$ by mouth weekly. We also prescribed naproxen, 500 $\mathrm{mg}$ twice per day, and hydrocodone, $5 \mathrm{mg}$ with acetaminophen $500 \mathrm{mg}$ as needed for breakthrough pain. The patient's primary provider also prescribed a baseline daily dose of prednisone, $10 \mathrm{mg}$ daily, in addition to an increase, then tapering schedule with an endpoint of $20 \mathrm{mg}$ daily. 


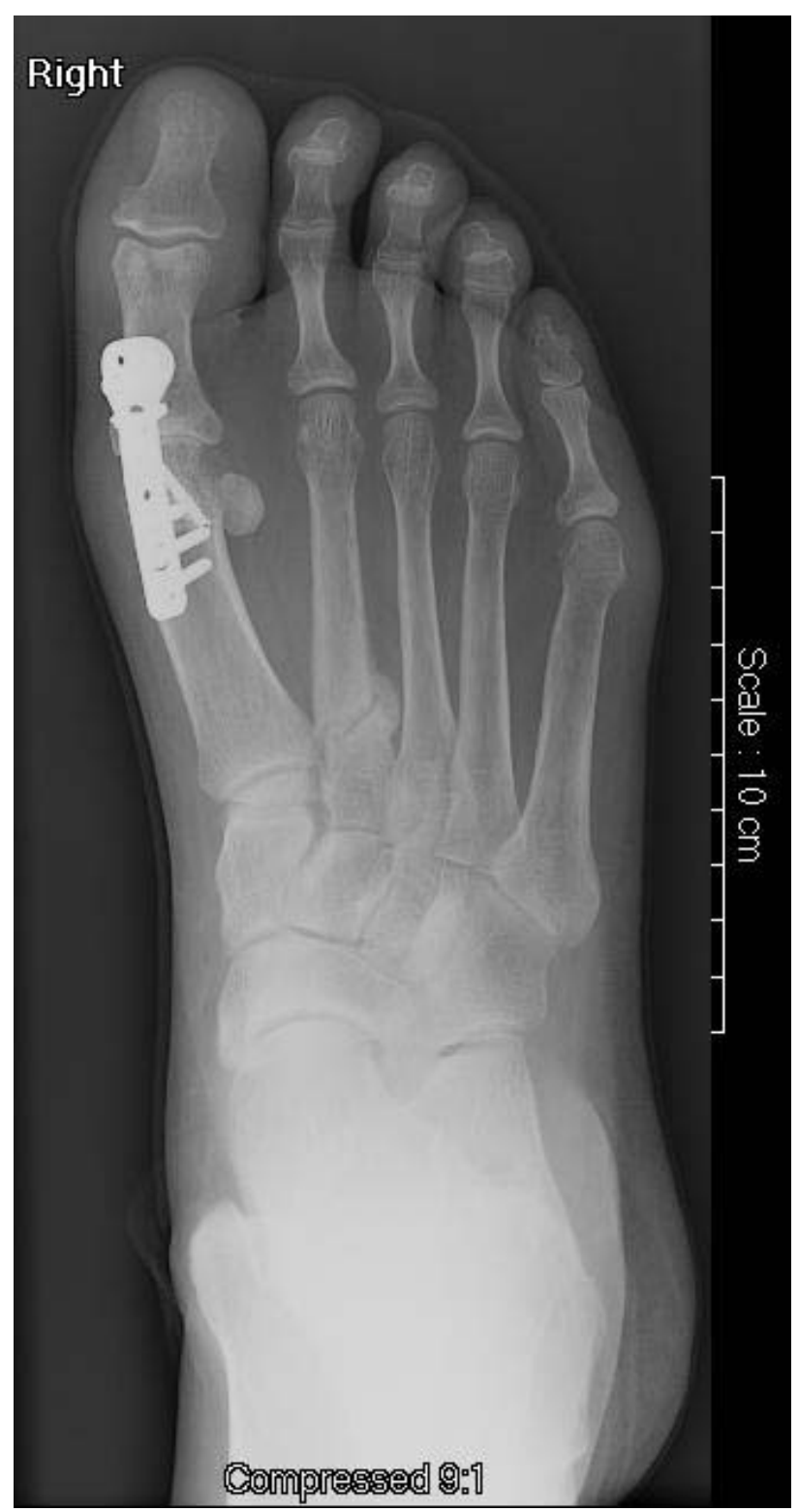

Figure 1 The 7 week postoperative anteroposterior radiograph demonstrating satisfactory placement of the CHARLOTTEE ${ }^{T M}$ MTP plate with screw fixation. The CHARLOTTE ${ }^{\text {TM }}$ Multi-Use Compression screw is also visible from medial distal to lateral proximal.

The patient is a non-smoker and did not have diabetes or peripheral neuropathy.

Medical treatment failed to provide pain relief, and shoe therapy combined with corticosteroid arthrocentesis was recommended. The patient's symptoms progressed and she was presented with several surgical options.
(C) The Foot \& Ankle Journal, 2008

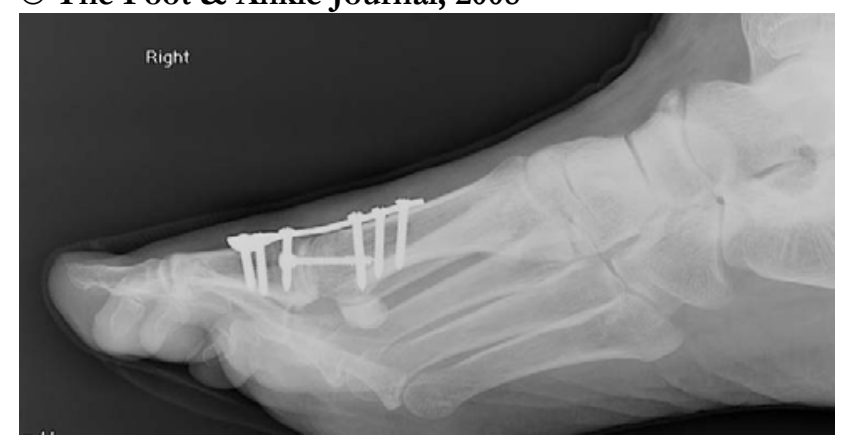

Figure 2 The 7 week postoperative lateral radiograph illustrating the low profile of the construct, with good purchase of all screw threads.

The patient underwent a first MTP arthrodesis procedure using the CHARLOTTE ${ }^{\mathrm{TM}}$ MTP Fusion System (Wright Medical Technology, Inc.). The surgery was uneventful, and radiographs taken 7 weeks postoperatively demonstrate adequate correction (Figs 1, 2).

The patient was kept immobilized for 3 months, ambulating in a cam walker for that entire time, and was subsequently discharged from postoperative care. Shortly after discharge, the patient relocated to another city in Montana.

The patient returned to the podiatry clinic 8 months later with a screw head percutaneously visible. There were no complaints of pain other than the concern over a visible screw head and associated dorsal edema. There was no reported history of trauma to the affected foot during the intervening time. Subsequent radiographs demonstrated loosening of the other screws and a failed union of the first MTP joint (Figs 3, 4).

The percutaneous screw was easily removed in the clinic with a hemostat. The patient returned to the operating room where all hardware was removed except for the initial transverse screw. The region of the non union and first metatarsal shaft was remodeled with demineralized bone matrix using Allomatrix ${ }^{\circledR}$ DR (Wright Medical Technology, Inc.). This was applied within the pseudo joint space along with another CHARLOTTE ${ }^{\mathrm{TM}}$ Multi-Use Compression screw. 


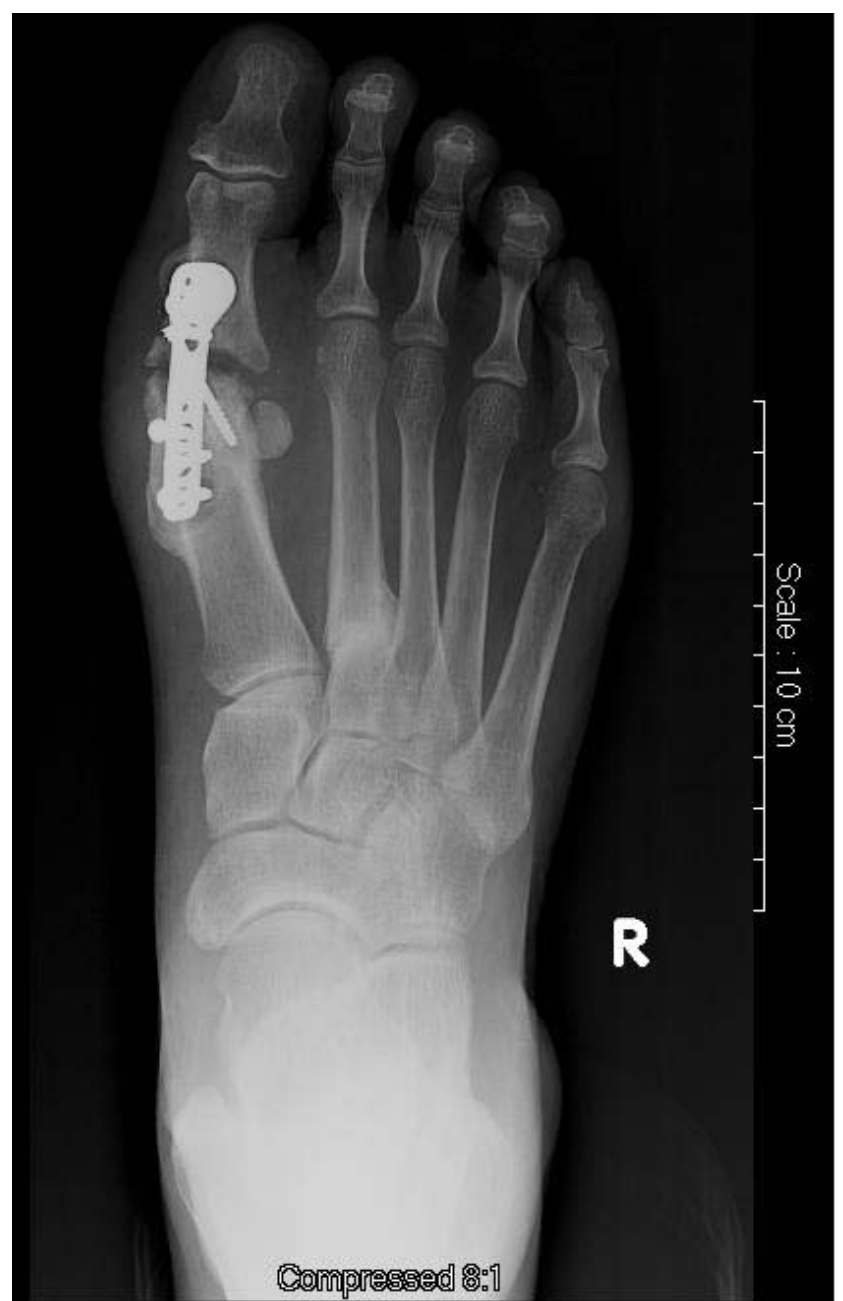

Figure $\mathbf{3}$

The 8 month postoperative anteroposterior radiograph clearly showing the non union, exuberant bone medial to the plate, and lucency of bone around the screws.

An Orthofix bone growth stimulator was fitted and dispensed to promote bone healing. Radiographs taken prior to the author's relocation indicated adequate progression of primary bone healing of the revised surgical site.

\section{Discussion}

The incidence of non union following arthrodesis of painfully diseased joints in rheumatoid arthritis patients is not unusual ${ }^{3,4}$ However, there is conflicting data suggesting a direct correlation between RA and surgical non union. ${ }^{9,10}$ Maenpaa et $\mathrm{al}^{9}$ state that non unions are more common among patients with severe deformity and

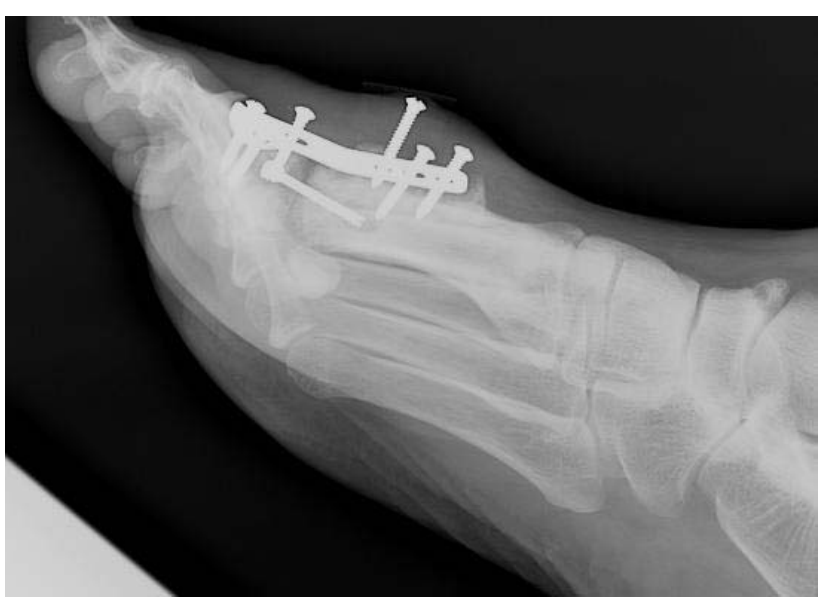

Figure 4 The 8 month postoperative lateral radiograph demonstrating the position of the percutaneous screw and loosening of the entire construct. The dorsal edema and visible screw head prompted the patient to return to the clinic.

osteoporosis (RA, neuromuscular arthropathy). In contradiction to the previous statement, Bogoch and Moran ${ }^{10}$ state that the relatively rapid and reliable bone healing and arthrodesis in RA may be attributable to the preexisting rapid turnover of bone with an increase in osteogenesis. These authors speculate that the phase of induction of osteogenesis initiated by surgical arthrodesis is enhanced by the preconditioned state of bone formation in this patient group. Other possible primary surgical approaches to consider in this case were hemi or total first implant arthroplasty verses resection arthroplasty (Keller procedure). This patient desired a rigid fusion. Another approach to revision could have been to remove all hardware and leave the non union alone, since she had no pain. Some studies show that non unions are not always painful. ${ }^{5}$ If successful, first MTP arthrodesis is a satisfactory procedure with good long-term results. ${ }^{5,6}$ The effects of poor bone healing with the use of oral prednisone are widely recognized. ${ }^{7}$ This may be considered a causative factor in this surgical result, but is purely speculative. The effect of an intra-articular corticosteroid injection in the final result of this case is also unknown. It is unlikely that joint injection with corticosteroid would have such a widespread effect on the massive failure of the entire construct. 
What is known is the increased risk of non union due to the patient's comorbidity of rheumatoid arthritis. The literature ${ }^{1,2}$ supports the notion that the incidence of rheumatoid arthritis in certain Native American tribes exceeds 5\%. While this author could not locate a specific reference to the incidence of RA in the Blackfeet Tribe of Montana, obeservations by two family doctors on this reservation over a 20 year period concur a similar incidence of the disease in the Blackfeet members they have treated. ${ }^{8}$ The pharmacy budget at the Blackfeet Community Hospital is significantly impacted by the cost of RA mitigating drugs.

In addition to medical morbidities, the foot and ankle surgeon must recognize rheumatoid arthritis as a factor that may impact the outcome of planned surgical procedures. High risk patients should be adequately counseled regarding risk factors and benefits verses possible adverse results. This should be carefully considered during the informed consent process. There seems to be a general consensus among foot and ankle surgeons that patients with RA have a higher risk of non union following surgical arthrodesis. The possibility of the increased risk of non union associated with RA in conjunction with ethnic ancestry cannot be positively correlated by this report and may merit further study of bone healing and genetic background.

\section{References:}

1. Cush, JJ, Kavanaugh, A. Rheumatoid Arthritis: Early Diagnosis and Treatment. Professional Communications, Inc., p 29. 2005.

2. Peschken, CA, Esdaile, JM. Rheumatic diseases in North America's indigenous peoples. Seminars in Arthritis and Rheumatism 28 (6), pp.368-391. 1999.

3. Anderson, T, Maxander, P, Rydholm, U, Besjakov, J, Carlsson, A. Ankle arthrodesis by compression screws in rheumatoid arthritis: Primary nonunion in $9 / 35$ patients. Acta Orthopaedica 76 (6), pp. 884-890. 2005.

4. Salai, M, Hakerem, D, Pritch, M, Chechick, A, Goshen, E. Non-union of undisplaced radial neck fracture in a rheumatoid patient. Archives of Orthopaedic and Trauma Surgery 119 (1-2), pp.119-120. 1999.

5. Goucher, NR, Coughlin, MJ. Hallux Metatarsophalangeal joint Arthrodesis using dome-shaped reamers and dorsal plate fixation: A prospective study. Foot and Ankle International 27 (11), pp. 869-876. 2006.

6. Brodsky, JW, Passmore, RN, Pollo, FE, Shabat, S. Functional outcome of Arthrodesis of the first metatarsalphalangeal joint using parallel screw fixation. Foot and Ankle International 26 (2), pp. 140-146. 2005.

7. Waters, RV, Gamradt, SC, Asnis, P, Vickery, BH, Avnur, Z, Hill, E, Bostrom, MPG. Systemic corticosteroids inhibit bone healing in a rabbit ulnar osteotomy model. Acta Orthopaedica Scandinavica 71 (3), pp. 316-321. 2000.

8. Personal communication, R. Rottenbiller, MD and R. Odegaard, MD. Blackfeet Community Hospital, Browning, Montana. 2007.

9. Maenpaa, H, Lehto, MUK, Belt, EA. Why Do Ankle Arthrodeses Fail in Patients with Rheumatic Disease? Foot \& Ankle International 22 (5), pp403-408. 2001.

10. Bogoch, ER, Moran, EL. Bone Abnormalities in the Surgical Treatment of Patients with Rheumatoid Arthritis. Clin. Orthop., 366, pp8-21. 1999. 